\title{
Evaluasi Proses Pembelajaran Dengan Pendekatan Systems Thinking
}

\author{
Casnan $^{1}$, Purnawan $^{2}$, Irman Firmansyah ${ }^{3}$, Heti Triwahyuni ${ }^{4}$ \\ casnan@upmk.ac.id ${ }^{1}$, purnawan.purnawan@pvto.uad.ac.id ${ }^{2}$, \\ irman_f@yahoo.com ${ }^{3}$, triwahyuniheti@upmk.ac.id ${ }^{4}$ \\ Sekolah Tinggi Keguruan dan Ilmu Pendidikan (STKIP) Muhammadiyah Kuningan ${ }^{1,4}$, \\ Universitas Ahmad Dahlan ${ }^{2}$, System Dinamics Center ${ }^{3}$
}

\section{Evaluation Of The Learning Process With The Systems Thinking Approach}

\begin{abstract}
A quality learning process is a learning process developed based on the results of the evaluation. One of the evaluations of the learning process is the systems thinking approach. This study aims to determine the constraints of the learning process with systems thinking approach and determine problem-solving strategies to improve the quality of the learning process. The research method used is a descriptive qualitative method and group model building. Based on the results of the study, it shows that the objective variable in the learning process is student understanding, the supporting variable to better understand the lecture material is the creativity of the lecturer.
\end{abstract}

Keywords: Evaluation, Learning, Systems Thinking

\section{Article Info}

Received date: 30 Mei $2021 \quad$ Revised date: 11 September 2021 Accepted date: 27 Januari 2022

\section{PENDAHULUAN}

Pendidikan adalah proses yang tidak dapat dipisahkan oleh manusia, karena dengan pendidikan, setiap individu bisa meningkatkan kemampuan intelektual, serta kemampuan mengkoordinasi berbagai persoalan. Pentingnya pendidikan bagi manusia dilihat dari peran yang dibawa dalam proses berlangsungnya kegiatan pembelajaran berkaitan dengan perkembangan kemampuan seseorang. Syah dalam (Rini, 2013: 3), menyatakan bahwa pendidikan berasal dari kata dasar "didik" yang artinya mempertahankan dan memberikan pelatihan. Pendidikan yang berkualitas dapat dicapai apabila proses pembelajaran yang dilakukan bisa berlangsung sesuai tujuan pembelajaran (Amirudin \& Muzaki, 2019:290). Menurut Bahri Djamarah (Pane \& Dasopang, 2017: 337), pembelajaran pada hakikatnya adalah suatu proses, yaitu proses mengatur, mengorganisasi lingkungan yang ada di sekitar peserta didik sehingga dapat menumbuhkan dan mendorong peserta didik melakukan proses belajar. Pembelajaran juga dikatakan sebagai proses memberikan bimbingan atau bantuan kepada peserta didik dalam melakukan proses belajar.

Menurut Nata (Pane \& Dasopang, 2017:342), tujuan pembelajaran adalah faktor yang sangat penting dalam proses pembelajaran. Dengan adanya tujuan pembelajaran, maka guru memiliki pedoman dan sasaraan yang akan dicapai dalam kegiatan belajar mengajar. Apabila tujuan pembelajaran sudah jelas dan tegas, maka langkah dan kegiatan pembelajaran akan lebih terarah. Tujuan dalam pembelajaran yang telah dirumuskan hendaknya disesuaikan dengan ketersediaan waktu, sarana prasarana dan kesiapan peserta didik. Sehubungan dengan hal itu, maka seluruh kegiatan guru dan peserta didik harus diarahkan pada tercapainya tujuan yang telah ditetapkan.

Jika dilihat dari sisi ruang lingkupnya, tujuan pembelajaran dapat dibagi menjadi dua bagian, yaitu: a) tujuan yang dirumuskan secara spesifik oleh guru yang bertolak dari materi pelajaran yang akan disampaikan. b) tujuan pembelajaran umum, yaitu tujuan pembelajaran yang sudah tercantum dalam garis-garis besar pedoman pengajaran yang dituangkan dalam rencana pengajaran yang disiapkan oleh guru. Sedangakan tujuan khusus yang dirumuskan oleh seorang guru harus memenuhi syaratsyarat, yaitu: a) secara spesifik menyatakan perilaku yang akan dicapai, b) Membatasi keadaan dimana pengetahuan perilaku diharapkan dapat terjadi (kondisi perubahan perilaku), c) Secara spesifik menyatakan criteria perubahan perilaku dalam arti menggambarkan standar minimal perilaku yang dapat diterima sebagai hasil yang dicapai. 
Dalam proses pembelajaran tentu tidak lepas dari berbagai permasalahan. Menurut Siregar \& Nara (Priyayi et al., 2018:87), mengelompokkan masalah yang ada dalam kegiatan belajar menjadi dua hal, yaitu masalah belajar internal dan masalah belajar eksternal. Masalah belajar internal merupakan masalah yang timbul dari diri siswa. Misalnya berkaitan dengan kesehatan, rasa aman, kemampuan intelektual, motivasi, usia, jenis kelamin, latar belakang sosial, kebiasaan belajar, kemampuan mengingat, dan kemampuan pengindraan, sedangkan masalah belajar eksternal adalah masalah-masalah yang timbul dari luar diri siswa. Misalnya terkait dengan kebersihan, udara, ruang belajar, alat belajar, dan lingkungan sosial. Faktor cara belajar yang buruk juga menjadi penyebab banyaknya siswa yang pandai tetapi hanya meraih prestasi yang tidak lebih baik dari siswa yang sebenarnya kurang pandai tetapi mampu meraih prestasi yang tinggi karena mempunyai cara belajar yang baik (Purwanto dalam Casnan et al., 2019: 54).

Agar permasalahan dalam proses pembelajaran bisa menemukan solusi, maka dalam melakukan evaluasi perlu dianalisis melalui suatu pendekatan. Pendekatan yang tepat dalam evaluasi pembelajaran yakni melalui systems thinking. Pendekatan systems thinking adalah untuk mengurangi adanya perilaku keterbatasan rasional yang dimiliki oleh manusia (O'conor dalam Trilestari \& Si, 2004: 72). Flood (Trilestari \& Si, 2004: 12), systems thinking merupakan cara memandang sesuatu secara keseluruhan, yang saling berhubungan. Memandang keseluruhan yakni mempelajari dalam memahami bagian yang terkait dalam suatu sistem. Senge (Trilestari \& Si, 2004: 12), mengatakan systems thinking adalah sesuatu yang terasa di seluruh elemen dan "saling terkait" karena mereka saling mempengaruhi diantara yang satu dengan yang lainnya secara terus menerus di setiap waktu dan bergerak menuju suatu tujuan secara umum. Oleh karena itu, penting sekali systems tingking untuk mengetahui masalah yang saling berhubungan antar variabel dalam proses pembelajaran dan mencari strategi untuk penyelesaian masalah pembelajaran untuk meningkatkan kualitas proses pembelajaran.

\section{KAJIAN PUSTAKA}

Pembelajaran adalah proses mengatur, mengorganisasi lingkungan di sekitar siswa sehingga menumbuhkan dan mendorong siswa melakukan proses belajar. Pembelajaran dikatakan sebagai proses memberikan bimbingan dan bantuan kepada siswa dalam proses belajar. Guru berperan sebagai pembimbing yang jumlahnya lebih sedikit dari siswa yang memiliki masalah. Dalam belajar banyak perbedaan, seperti dalam mencerna materi pelajaran, ada siswa yang sulit mencerna materi pelajaran. Dengan danya perbedaan ini, guru harus mampu menyesuaikan sesuai kebutuhan para siswa.

Maka dari itu pembelajaran adalah peraturan dan hakikat belajar adalah suatu perubahan (Djamarah dalam Pane \& Dasopang:337). Dageng dalam (Taslimah, 2011: 9), pembelajaran adalah upaya untuk membelajarkan siswa. Sedangkan menurut Hamzah (Taslimah, 2011:9), menyatakan istilah pembelajaran memiliki hakekat perencanaan atau perancangan sebagai upaya untuk membelajarkan siswa. Nasution (Festiawan, 2020:11) pengertian pembelajaran adalah kegiatan mengatur lingkungan sebaik-baiknya dan menghubungkannya dengan siswa sehingga terjadi proses belajar. Menurut Gulo (Festiawan, 2020:12) pembelajaran adalah usaha untuk menciptakan sistem lingkungan yang bisa mengoptimalkan kegiatan belajar.

Pembelajaran adalah usaha membuat siswa mau belajar, dan menciptakan suatu situasi atau peristiwa belajar (event of learning) agar terjadi perubahan tingkah laku siswa. pembelajaran adalah proses yang diselenggarakan oleh guru untuk membelajarkan siswa dalam belajar, bagaimana belajar memperoleh dan memproses pengetahuan, ketrampilan dan sikap (Gagne \& Briggs dalam Hasnawati, 2017:55). Chauhan (Sunhaji, 2014:33) mengatakan pembelajaran adalah upaya memberi (stimulus), bimbingan, pengarahan dan dorongan kepada siswa. Tak hanya itu, pembelajaran adalah kombinasi meliputi unsur-unsur manusiawi, material, fasilitas, perlengkapan dan prosedur yang saling mempengaruhi untuk mencapai tujuan pembelajaran (Gerry \& Kingsley dalam Sunhaji, 2014:33). Bisa disimpulkan bahwa pembelajaran merupakan suatu proses mengatur siswa atau peserta didik agar bisa mencapai tujuan yang diharapkan dalam hal ini siswa memiliki kemampuan yang baik bak dari segi kognitif, afektif maaupun psikomotornya. Pada intinya pembelajaran adalah interaksi antara guru dan siswa.

Dalam pelaksanaan proses pembelajaran, sering kali tujuan pembelajaran tidak tercapai. Itu semua diakibatkan dari berbagai permasalahan. Menurut Syahril dan Ahmad (Syafni et al., 2013:15) masalah adalah kegagalan individu dalam memenuhi kebutuhan sehingga mengakibatkan 
ketidakseimbangan. Permasalahan dalam proses pembelajaran adalah keadaan yang dialami seorang individu dan menghambat proses pembelajaran (Amti dan Marjohan dalam Syafni et al., 2013:15). Permasalahan tersebut harus diatasi karena pembelajaran yang berhasil ditentukan oleh bagaimana proses pembelajaran berlangsung di sekolah. Keberhasilan proses pembelajaran disebabkan dari berbagai faktor begitu juga menurut Nurkolis (Hera, 2017:53) bahwa keberhasilan pendidikan di sekolah ditentukan dari bagaimana proses pembelajaran. Berhasil tidaknya pembelajaran dalam mencapai tujuan dilihat setelah dilakukannya evaluasi dan mendapatkan hasil. Jika hasil tidak sesuai dengan tujuan maka perlu sekali faktor yang menjadi permasalahan agar dipertimbangkan. Dengan begitu, evaluasi pembelajaran sangat penting dalam proses pendidikan.

Secara etimologis, evaluasi berasal dari bahasa Inggris, "evaluation" artinya penilaian. Menurut Arikunto (Izza et al., 2020: 11), evaluasi memiliki arti menilai (dilakukan pengukuran terlebih dahulu). Evaluasi terdapat dua langkah yang harus dilakukan yaitu mengukur dan menilai. Mengukur adalah membandingkan sesuatu dengan satu ukuran, pengukuran bersifat kuantitatif. Adapun menilai adalah mengambil suatu keputusan terhadap sesuatu dengan ukuran baik buruk, penilaian bersifat kualitatif. Arifin dalam (Izza et al., 2020: 11), bahwa evaluasi adalah proses yang sistematis dan berkelanjutan untuk menentukan kualitas (nilai dan arti) sesuatu, berdasarkan pertimbangan dan kriteria tertentu dalam rangka mengambil keputusan. Evaluasi pembelajaran adalah inti bahasan evaluasi yang kegiatannya di lingkup proses belajar-mengajar. Evaluasi pembelajaran berkaitan dengan apa yang dilakukan guru dalam menyampaikan materi pembelajaran kepada siswa. Bagi seorang guru, evaluasi pembelajaran adalah media yang tidak terpisahkan dari kegiatan mengajar, karena melalui evaluasi seorang guru akan mendapatkan informasi tentang pencapaian hasil belajar. Dengan melakukan evaluasi, apakah materi yang diajarkan seseuai atau tidak dengan para siswa (Sukardi dalam Haryanto, 2020). Dari berbagai pengertian dapat disimpulkan evaluasi adalah tindakan atau suatu proses untuk menentukan nilai keberhasilan yang telah dilakukan.

\section{Systems Thinking}

Systems thinking merupakan gambaran sesuatu secara menyeluruh dan mempunyai keterkaitan diantara variabel 10 , maka hasil dari suatu proses systems thinking dapat digambarkan dalam suatu model. Model adalah suatu pengganti dari suatu obyek atau sistem. Nadler (Trilestari, 2004:73), merumuskan model sebagai kerangka kerja, skema yang teratur atau peta jalan yang dapat membantu kita memahami dan meramalkan perilaku organisasi. 11 Metodologi pemodelan sistem, mempelajari cara-cara yang digunakan untuk memperlakukan aspek dinamis dan komplek dari suatu sistem. Forrester (Trilestari, 2004:73), mengatakan bahwa model merupakan dasar dari penelitian eksperimental yang relatif murah dan hemat waktu dibandingkan dengan bila mengadakan percobaan pada sistem yang sesungguhnya. Oleh karena itu, observasi dari suatu permasalah organisasi dapat dibuatkan dalam model-model sistem. Dengan demikian systems thinking dapat menghasilkan model yang sering disebut sebagai causal loop diagram (CLD). Arnold dan Wade dalam (Betley et al., n.d., 2021: 12) mendefinisikan systems thinking adalah "seperangkat keterampilan analitik sinergis yang digunakan untuk meningkatkan kemampuan mengidentifikasi dan memahami sistem, memprediksi perilaku mereka, dan merancang modifikasi untuk mereka menghasilkan efek yang diinginkan. " Ini menjadi hal yang berguna dalam mencoba memahami pemikiran sistem. Sama halnya dengan penelitian yang dilakukan oleh (Izza et al., 2020), (Widoyoko, 2000), dan (Budi, 2021) bahwa evaluasi pembelajaran memiliki penting untuk mencapai tujuan pembelajaran yang sudah ditentukan. Begitu juga dengan penelitian (Arndt, 2006), (Henriksen \& Aas, 2020), dan (Shams et al., 2020) menyatakan bahwa penggunaan systems thinking sangatlah penting juga mampu memberikan gambaran terkait permasalahan maupun suatu hal yang sedang menjadi pembahasan. Dengan begitu, evaluasi proses pembelajaran dengan pendekatan systems thinking sangat penting untuk kemajuan dalam proses pembelajaran.

\section{METODE PENELITIAN}

Metode penelitian yang digunakan adalah metode deskriptif kualitatif. Menurut Winartha (Lindawati, 2016: 834), metode deskriptif kualitatif yaitu menganalisis, menggambarkan, dan meringkas berbagai kondisi, situasi dari berbagai data yang dikumpulkan umunya berupa hasil wawancara atau pengamatan mengenai masalah yang diteliti yang terjadi di lapangan. 
Proses pengambilan data dilakukan melalui FGD atau Grup Model Building yang merupakan suatu metode pemecahan masalah yang memerlukan beberapa jawaban alternatif dan dapat mendekati kebenaran yang sebenarnya. Beberapa pendapat dari para ahli dan steakholder yang terlibat dalam proses pembelajaran dapat dijadikan suatu referensi untuk membuat evaluasi proses pembelajaran dengan pendekatan systems thinking. Tahapan yang dilakukan dalam memperoleh data yakni Data yang dikumpulkan berupa perolehan informasi dari hasil diskusi dalam suatu kelompok pengajar yang berfokus membahas permasalahan dalam proses pembelajaran. Data atau informasi yang didapatkan kemudian diproses melalui systems thinking.

Menurut (Hartono, 2017:4) setelah data informasi didapatkan, langkah yang dilakukan adalah: 1) menganalisis rekaman proses diskusi, 2) mengelompokkan setiap pernyataan dari tiap individu, 3) menandai hal penting di dalam catatan atau transkrip, 4) menyimpulkan pendapat dan reaksi peserta terhadap topik permasalahan pembelajaran melalui systems thinking.

\section{HASIL PENELITIAN DAN PEMBAHASAN}

Hasil penelitian ini menunjukan hubungan keterkaitan antara variabel yang ditunjukan melalui peta konsep yang digambarkan.

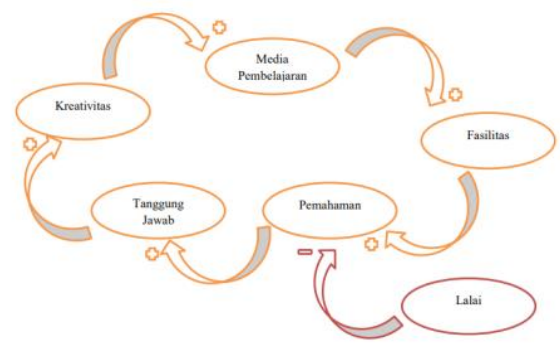

Gambar 1. Hubungan keterkaitan variabel dalam proses pembelajaran kelompok 1

Berdasarkan gambar kelompok 1, berkaitan tentang hubungan keterkaitan variabel dalam proses pembelajaran bahwa komponen media pembelajaran, fasilitas, pemahaman, serta tanggung jawab seorang siswa sangat berkaitan. Media pembelajaran menurut Hamalik merupakan alat yang digunakan guna mempermudah proses pembelajaran sehingga pembelajaran menjadi efektif dan efisien. Media pembelajaran disajikan melalui alat yang termasuk ke dalam suatu fasilitas. Mulyasa (Rizal, 2020:4), menyatakan bahwa fasilitas pembelajaran berkaitan dengan sarana dan prasarana yang ada di sekolah. Sarana tersebut adalah peralatan juga perlengkapan mendukung proses pembelajaran seperti gedung, ruang kelas, meja kursi, serta alat-alat dan media pembelajaran. Sedangkan prasarana adalah fasilitas yang tidak langsung menunjang proses pendidikan atau pembelajaran seperi halaman, ruangan kelas, udara, dll. Dengan adanya media pembelajaran serta fasilitas yang baik tentu dapat meningkatkan pemahaman siswa serta tanggung jawab dalam memperoleh informasi pembelajaran. Keberadaan fasilitas belajar sebagai penunjang ini sesuai dengan pendapat Arsyad (Khairunisa, 2020:147) bahwa sarana belajar dapat memberikan manfaat untuk meningkatkan dan menggairahkan perhatian anak sehingga dapat menimbulkan motivasi belajar. Jika motivasi belajar sudah ada pada diri siswa, maka dengan sendirinya akan meningkatkan pemahaman siswa dan mempengaruhi hasil belajar siswa. Sejalan dengan penelitian (Febriani \& Sarino, 2017:9), bahwa fasilitas juga cara belajar (menggunakan media) memberikan pengaruh yang signifikan terhadap prestasi belajar siswa (Wijayanti dalam Febriani \& Sarino, 2017:10).

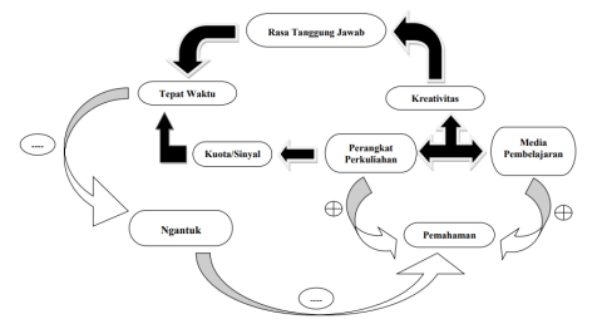

Gambar 2. Hubungan keterkaitan variabel dalam proses pembelajaran kelompok 2 
Dari bagan hubungan keterkaitan dalam proses pembelajaran kelompok 2 bahwa media pembelajaran berkaitan erat dengan perangkat perkuliahan. Perangkat pembelajaran dalam perkuliahan yakni mencangkup peta konsep, silabus mata kuliah, Rencana Pembelajaran Semester (RPS), Rencana Proses pembelajaran (RPP), Rancangan Tugas Mahasiswa (RTM), Lembar Kerja Mahasiswa (LKM), dan lembar penilaian hasil belajar (Monalisa \& Trapsilasiwi, 2016: 194).Tak hanya itu, perangkat perkuliahan saat ini yang diperlukan adalah kuota atau sinyal seperti pendapat Kurniati (Rachman, 2020:323) bahwa aspek yang diperhatikan dalam online learning adalah siswa, guru, materi pembelajaran, teknologi atau platform yang digunakan, dan lingkungan pembelajaran. Dari perangkat perkuliahan yang baik serta media pembelajaran yang menunjang, dapat dilihat bahwa kreatifitas mahasiswa bisa menimbulkan tanggung jawab dan menjadikan seorang mahasiswa menjadi disiplin juga tepat waktu baik saat mengikuti perkuliahan maupun saat mengerjakan tugas.

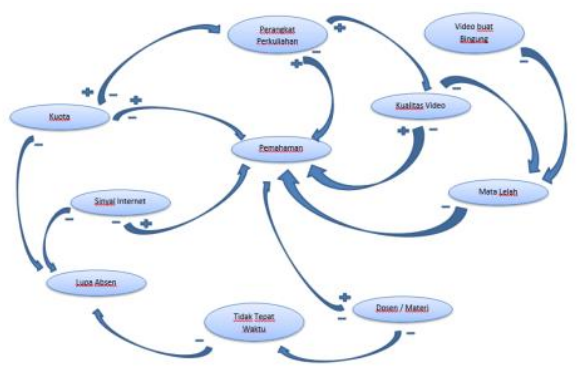

Gambar 3. Hubungan keterkaitan variabel dalam proses pembelajaran kelompok 3

Berkaitan dengan hubungan keterkaitan variabel dalam proses pembelajaran kelompok 3, terlihat bahwa perangkat perkuliahan bisa mempengaruhi terhadap pemahaman mahasiswa dalam proses pembelajaran berlangsung. Misalnya pembuatan media video merupakan suatu inovasi pembelajaran, akan tetapi apabila faktor lain seperti fisik mahasiswa yang kurang sehat, kualitas video kurang baik tentu mengurangi terhadap pemahaman mahasiswa (Casnan et al., 2018:54). Sama halnya dengan penelitian (Lestari, 2017) bahwa inovasi pembelajaran dapat dilakukan melalui berbagai variasi baik itu metode, model dan media agar penyampaian materi bisa lebih kreatif sehingga siswa menjadi fokus juga antusias saat menerima pembelajaran. Sama haJadi pada intinya jika faktor pendukung mengalami permasalahan maka faktor itu akan menjadi penghambat bagi mahasiswa dalam memahami pembelajaran.

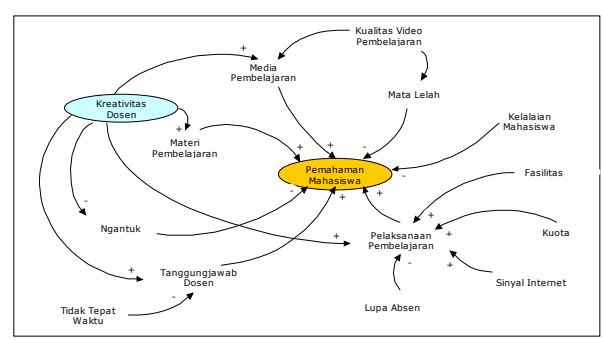

Gambar 4. Hubungan keterkaitan variabel dalam proses pembelajaran berdasarkan grup model buliding

Dari gambar 4, hubungan keterkaitan variabel dalam proses pembelajaran berdasarkan grup model building menimbulkan 2 arah panah yakni panah masuk dan panah keluar. Panah yang masuk yakni mengarah pada pemahaman siswa atau mahasiswa sebagai tujuan utama yang ingin dicapai dalam proses pembelajaran. Tujuan ini dipengaruhi dari panah yang masuk seperti pada gambar yakni media pembelajaran, kualitas video, pelaksanaan pembelajaran, dan dosen. Sedangkan arah panah keluar merupakan kendala utama dalam proses pembelajaran. Yang mempengaruhi serta menjadi faktor terhadap kendala pembelajaran yakni kelelahan, mengantuk, kurang disiplin, dan fasilitas penunjang pelajaran yang kurang memadai (Syarifuddin, 2011:121). Menurut Sterman (Scott, 2018: 2), group model building adalah proses kelompok yang menghasilkan pembangunan model untuk menggambarkan hubungan sebab akibat antara komponen suatu sistem, dalam suatu peta diagram lingkaran yang memperlihatkan sebab akibat, pengaruh, aliran, dan dinamik simulasi. Maka dari itu, dengan penggunaan grup model building tentu mempermudah analisis sebab akibat, khususnya dalam melihat faktor terhadap keberhasilan suatu pembelajaran. 
Evaluasi Proses Pembelajaran Dengan Pendekatan Systems Thinking

(Casnan, Purnawan, Irman Firmansyah, Heti Triwahyuni)

\section{Strategi Pemecahan Masalah}

Tabel 1. Strategi Pemecahan Masalah

\begin{tabular}{|c|c|c|}
\hline No & Kendala & Program \\
\hline 1 & Sinyal Internet & $\begin{array}{l}\text { 1. Mencari daerah terdekat yang ada sinyal internet } \\
\text { 2. Kuliah Offline }\end{array}$ \\
\hline 2 & Kuota & 1. Subsidi Kuota \\
\hline 3 & Fasilitas/alat perkuliahan & $\begin{array}{l}\text { 1. Membuat video pembelajaran yang dapat diputar ulang } \\
\text { 2. Kuliah Offline }\end{array}$ \\
\hline 4 & Media Pembelajaran & $\begin{array}{l}\text { 1. Memberikan softcopy sumber belajar seperti ebook } \\
\text { 2. Mencari sumber referensi lain } \\
\text { 3. Membuat video pembelajaran interaktif dengan resolusi yang } \\
\text { tinggi } \\
\text { 4. Penamaan judul video Media Pembelajaran di youtube }\end{array}$ \\
\hline 5 & Pemahaman Materi lambat & $\begin{array}{l}\text { 1. Komunikasi Dosen dan mahasiswa } \\
\text { 2. Membuat video pembelajaran yang dapat diputar ulang } \\
\text { 3. Mencari sumber referensi lain } \\
\text { 4. Memperbanyak pembahasan contoh soal }\end{array}$ \\
\hline 6 & Lupa Mengisi Absen & $\begin{array}{l}\text { 1. Perpanjang waktu pengisian presensi } \\
\text { 2. Saling mengingatkan } \\
\text { 3. } \text { Mengaktifkan alarm }\end{array}$ \\
\hline 7 & Mata Lelah & 1. Perpanjang waktu perkuliahan \\
\hline 8 & $\begin{array}{l}\text { Dosen Jarang Masuk/Tidak } \\
\text { Memberi Materi }\end{array}$ & $\begin{array}{l}\text { 1. Diingatkan } \\
\text { 2. Meminta materi perkuliahan } \\
\text { 3. Meminta ganti dosen }\end{array}$ \\
\hline 9 & $\begin{array}{l}\text { Tidak Tepat } \\
\text { Waktu/Dadakan }\end{array}$ & $\begin{array}{l}\text { 1. Membuat kesepakatan dengan dosen } \\
\text { 2. Diingatkan }\end{array}$ \\
\hline 10 & Ngantuk & $\begin{array}{l}\text { 1. Ice breaking pada saat proses pembelajaran } \\
\text { 2. Memberikan pertanyaan-pertanyaan mengenai materi perkuliahan } \\
\text { 3. Memberikan tugas menyimpulkan mengenai materi perkuliahan }\end{array}$ \\
\hline 11 & Kreativitas Dosen & $\begin{array}{l}\text { 1. Pelatihan public speaking dosen } \\
\text { 2. Pelatihan membuat media pembelajaran } \\
\text { 3. Evaluasi proses pembelajaran yang telah dilakukan oleh dosen } \\
\text { 4. Memberikan reward untuk dosen yang kreatif dan inovatif } \\
\text { 5. Memperbanyak sumber referensi }\end{array}$ \\
\hline 12 & Kelalaian Mahasiswa & $\begin{array}{l}\text { 1. Saling mengingatkan } \\
\text { 2. } \text { Mengaktifkan alarm }\end{array}$ \\
\hline
\end{tabular}

Dari hasil group model building maka bisa dibuat suatu program terkait persoalan atau kendala dalam mencapai tujuan pembelajaran. Seperti sinyal internet, yang mana ditemukan juga solusi untuk mengatasinya dengan cara mencari daerah yang sinyalnya bagus, dan beberapa kendala lainnya (Hatmo, 2021:119). Dengan adanya group model building, setiap komponen yang mempengaruhi bisa dianalisis juga dapat ditemukan solusinya sebagai strategi atau cara memecahkan permasalahan.

\section{SIMPULAN DAN SARAN}

Berdasarkan hasil group model building menunjukan bahwa variabel tujuan dalam proses pembelajaran adalah pemahaman mahasiswa, variabel penunjang untuk lebih memahami materi perkuliahan adalah kreativitas dosen. Dengan adanya penelitian ini diharapkan bisa menjadi rujukan bagi pembaca yang ingin melalukan evaluasi pembelajaran menggunakan systems thinking.

\section{UCAPAN TERIMAKASIH}

Ucapan terimakasih kepada System Dynamics Center (SDC) telah mendukung kegiatan penelitian ini. 


\section{DAFTAR PUSTAKA}

Amirudin, \& Muzaki, I. A. (2019). Life Skill Education and It's Implementation in Study Programs Islamic Religious Education. Jurnal Tarbiyah, 26(2), 278-293. https://doi.org/10.30829/tar.v26i2.485

Anita Rahman, S. (2020). Penguatan Peran Orang Tua dalam Mendapingi Pendidikan Anak Usia Dini di Masa Pandemi Covid-19. Jurnal Golden Age, 4(02), 322-331. https://doi.org/10.29408/jga.v4i02.2520

Arndt, H. (2006). Enhancing System Thinking in Education Using System Dynamics. Simulation, 82(11), 795-806. https://doi.org/10.1177/0037549706075250

Betley, E., Sterling, E. J., Porzecanski, A. L., Betley, E., Sterling, E. J., \& Porzecanski, A. L. (n.d.). Network of Conservation Educators and Practitioners The Value of Systems Thinking in a Rapidly Changing World. 11(1), 5-8.

Budi, D. R. (2021). Evaluasi Pembelajaran Senam di Masa Pandemi Covid 19 Berbasis e-Learning Eldiru. 1-7.

Casnan, C., Mahpudin, A., \& Puadi, E. F. W. (2018). Penerapan Permainan Interaktif Geocaching Untuk Meningkatkan Motivasi Siswa dalam Belajar sebagai Inovasi Baru Pembelajaran Matematika. UNION: Jurnal Ilmiah Pendidikan Matematika, 6(1), 53-60. https://doi.org/10.30738/.v6i1.2028

Casnan, Mahpudin, \& Puadi. (2019). Penerapan Permainan Interaktif Geocaching untuk Meningkatkan Motivasi Siswa dalam Belajar sebagai Inovasi Baru Pembelajaran Matematika. UNION: Jurnal Ilmiah Pendidikan Matematika, July 2020. https://doi.org/10.17509/edusentris.v4i2.374

Febriani, P. S., \& Sarino, A. (2017). Dampak Cara Belajar dan Fasilitas Belajar dalam Meningkatkan Prestasi Belajara Siswa Sekolah Menengah Kejuruan. Manajerial, 2(2), 163-172.

Festiawan, R. (2020). Belajar dan Pendekatan Pembelajaran (hal. 1-17).

Hartono, S. (2017). Tata cara pelaksanaan Focus Group Discussion ( FGD ) atau Diskusi Kelompok Terarah ( DKT) (hal. 1-5).

Haryanto. (2020). Evaluasi Pembelajaran; Konsep dan Manajemen. In UNY Press. http://staffnew.uny.ac.id/upload/131656343/penelitian/EVALUASI PEMBELAJARAN.pdf

Hasnawati. (2017). Pendekatan Contextual Teaching Learning. Jurnal Ekonomi \& Pendidikan, 3, 5362.

Hatmo, S. H. D. (2021). Dampak Pandemi Covid-19 terhadap Efektivitas Pembelajaran Jarak Jauh secara Daring. Scholaria: Jurnal Pendidikan dan Kebudayaan, 11(2), 115-122.

Henriksen, Ø. H., \& Aas, M. (2020). Enhancing System Thinking - a Superintendent and Three Principals Reflecting with a Critical Friend. Educational Action Research, 00(00), 1-16. https://doi.org/10.1080/09650792.2020.1724813

Hera, R. (2017). Studi Kasus Permasalahan Dalam Proses. Genta Mulia, VIII(1), 53-63.

Izza, A. Z., Falah, M., \& Susilawati, S. (2020). Studi Literatur : Problematika Evaluasi Pembelajaran dalam Mencapai Tujuan.

Khairunisa, R. (2020). Pengaruh Fasilitas Belajar terhadap Motivasi Belajar Siswa Kelas V di SDN 001 Samarinda Utara. Pendas Mahakam: Jurnal Pendidikan Dasar, 4(2), 146-151. https://doi.org/10.24903/pm.v4i2.404

Lestari, A. (2017). Keefektifan Media Audio Visual sebagai Kreativitas Guru Sekolah Dasar dalam Menumbuhkan Keterampilan Menulis Puisi Siswa. Scholaria: Jurnal Pendidikan dan Kebudayaan, 7(3), 214. https://doi.org/10.24246/j.scholaria.2017.v7.i3.p214-225 
Evaluasi Proses Pembelajaran Dengan Pendekatan Systems Thinking

(Casnan, Purnawan, Irman Firmansyah, Heti Triwahyuni)

Lindawati, S. (2016). Penggunaan Metode Deskriptif Kualitatif untuk Analisis Strategi Pengembangan Kepariwisataan Kota Sibolga Provinsi Sumatera Utara. Seminar Nasional APTIKOM (SEMNASTIKOM), Hotel Lombok Raya Mataram, 833-837.

Monalisa, L. A., \& Trapsilasiwi, D. (2016). Pengembangan Perangkat Pembelajaran Mata Kuliah Teori Bilangan Program Studi Pendidikan Matematika Berdasarkan Kurikulum Kerangka Kualifikasi Nasional Indonesia (KKNI). Pancaran Pendidikan, 5(4), 191-200.

Pane, A., \& Darwis Dasopang, M. (2017). Belajar dan Pembelajaran. FITRAH:Jurnal Kajian Ilmu-ilmu Keislaman, 3(2), 333. https://doi.org/10.24952/fitrah.v3i2.945

Priyayi, D. F., Keliat, N. R., \& Hastuti, S. P. (2018). Masalah dalam Pembelajaran menurut Perspektif Guru Biologi Sekolah Menengah Atas (SMA) Di Salatiga dan Kabupaten Semarang. Didaktika Biologi: Jurnal Penelitian Pendidikan Biologi, 2(2), 85-92.

Rini, Y. S. (2013). Pendidikan: Hakekat, Tujuan, dan Proses. Jogyakarta: Pendidikan Dan Seni Universitas Negeri Jogyakarta.

Rizal, A. S., \& Nurjaya. (2020). Pengaruh Keterampilan Kepala Sekolah, Budaya Kerja, dan Fasilitas Pembelajaran terhadap Kinerja Guru SD Pada Yayasan Tadika Puri Anis. Journal of Chemical Information and Modeling, 53(9).

Scott, R. (2018). Group Model Building: Using Systems Dynamics to Achieve Enduring Agreement. http://www.springer.com/series/11467

Shams Esfandabadi, Z., Ravina, M., Diana, M., \& Zanetti, M. C. (2020). Conceptualizing Environmental Effects of Carsharing Services: a System Thinking Approach. Science of the Total Environment, 745(July). https://doi.org/10.1016/j.scitotenv.2020.141169

Sunhaji, S. (2014). Konsep Manajemen Kelas dan Implikasinya dalam Pembelajaran. Jurnal Kependidikan, 2(2), 30-46. https://doi.org/10.24090/jk.v2i2.551

Syafni, E., Syukur, Y., \& Ibrahim, I. (2013). Masalah Belajar Siswa dan Penanganannya. Konselor, 2(2), 15-19. https://doi.org/10.24036/02013221721-0-00

Syarifuddin, A. (2011). Penerapan Model Pembelajaran Cooperative Belajar dan Faktor-Faktor yang Mempengaruhinya. Ta'dib:Journal of Islamic Education (Jurnal Pendidikan Islam), 16(01), 113-136. https://doi.org/10.19109/tjie.v16i01.57

Taslimah, S. (2011). Peningkatan Motivasi Belajar Matematika pada Segiempat dengan Pendekatan Aptitude Treatment Interaction (PTK) Pembelajaran Matematika Bagi Siswa Kelas VII Semester Genap MTs Negeri Andong Boyolali Tahun Ajaran 2010/2011). 8-19.

Trilestari, E. W. (2004). Systems Thinking dan System Dynamics sebagai Suatu Pendekatan dalam Pengukuran Kinerja Pelayanan B. Keunggulan Pendekatan Systems Thinking dan System Dynamics. 71-81.

Widoyoko, E. P. (2000). Evaluasi Program Pembelajaran. Jurnal Ilmu Pendidikan, 1-16. 